\title{
НОВОЕ ЗНАЧЕНИЕ КЛЮЧЕВОЙ СТАВКИ И РЫНОК ИПОТЕЧНОГО КРЕДИТОВАНИЯ В 2021 ГОДУ
}

\section{THE NEW KEY RATE VALUE \\ AND THE MORTGAGE MARKET IN 2021 \\ E. Metreveli}

Summary. The article examines the main aspects that are predicted by experts in the field of mortgage lending, which can be expected as a result of the rise in the key rate. Analysts note that mortgage rates themselves are not expected to rise. However, the associated costs can increase significantly. Also, concessional lending programs are ending. This will generally have a negative impact on the mortgage market, which is expected to shrink in the very near future.

Keywords: key rate, mortgage market, credit, Central Bank, commercial real estate.
Метревели Елизавета Георгиевна

Аспирант, Преподаватель, МПЭК РЭу

им. Г.В. Плеханова

metrevelieg@yandex.ru

Аннотация. В статье рассматриваются основные аспекты, которые прогнозируются экспертами в области ипотечного кредитования, которые можно ожидать в результате состоявшегося подъема ключевой ставки. Аналитиками отмечается, что не ожидается роста самих ипотечных ставок. Однако сопряженные с этим расходы могут возрасти существенно. Также заканчивают свое действие льготные программы кредитования. Это, в целом, окажет негативное воздействие на рынок ипотечного кредитования, который, как ожидается, сузится в самое ближайшее время.

Ключевые слова: ключевая ставка, рынок ипотечного кредитования, кредит, Центробанк, коммерческая недвижимость.

новая волна. Тогда высокая ключевая ставка окажет крайне негативное воздействие на неуспевший оправиться от потрясений рынок ипотечного кредитования.

Изменения ставок по ипотеке являются важным фактором при принятии решения о покупке домов или рефинансировании существующих ипотечных кредитов. Это заставляет задуматься о детерминантах, обусловливающих рост или падение ставок по ипотеке. Существует несколько факторов, которые влияют на ставки по ипотеке. В целом, рост экономики приводит к более высоким ставкам по ипотечным кредитам, в то время как замедление роста экономики приводит к более низким ставкам по ипотечным кредитам. Центробанк устанавливает более высокую ключевую ставку, которая часто коррелирует с более высокими ставками по ипотеке для покупателей жилья.

Экспертами высказывается мнение, что принятое решение Центробанком России по повышению ключевой ставки незначительно повлияет на ставки по ипотечному кредитованию. В то же время, указывается, что с высокой степенью вероятности возрастут расходы, которые возникают при оформлении ипотеки, а также иных банковских продуктов.

В апреле состоялось повышение Центробанком России ключевой ставки на 0,5 п.п. до 5\%. Следует отметить, что данный шаг входил в число малоожидаемых действий и, по мнению большинства экспертов, и будет 


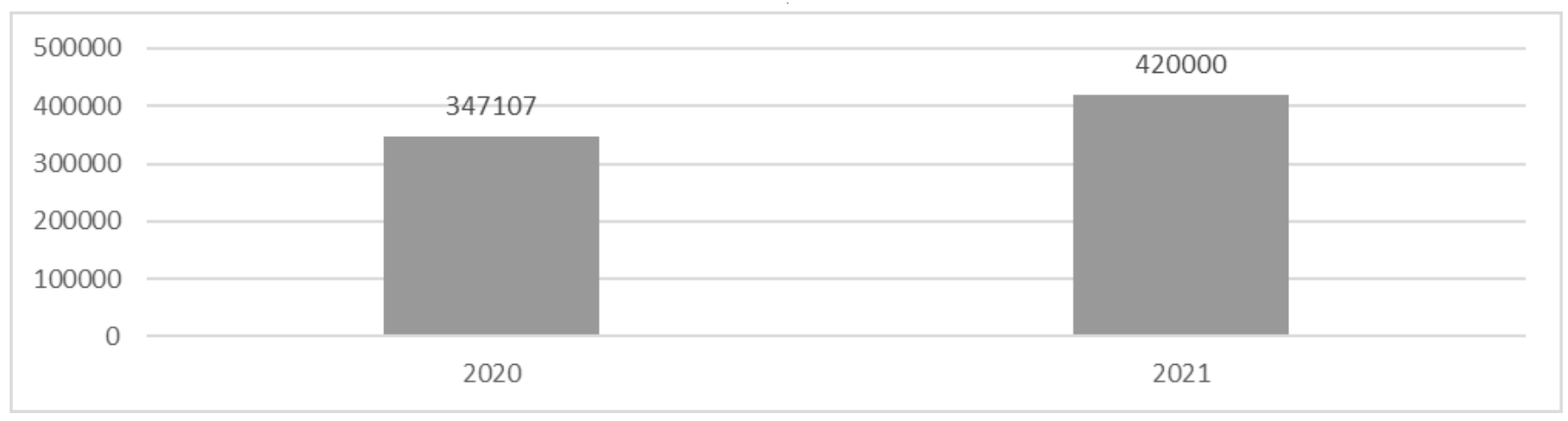

Рис. 1. Соотношение числа ипотечных кредитов в 2020 и 2021 гг. [5]

рассматриваться как непопулярная мера кредитно-денежной политики, за которую Центробанк России будет критиковаться многими специалистами и самим населением страны, на которое будут возложены основные тяготы по реализации данного решения. Непопулярность принятого решения усиливается в связи с тем, что месяцем ранее уже состоялось увеличение ставки на 0, 25 п.п [2].

Также регулятор прогнозирует, что значение ключевой ставки в этом году будет колебаться в пределах $4,8-5,4 \%$.

И вот в момент написания данной статьи происходит новое решение Совета директоров Банка России от 11 июня 2021 года по очередному повышению ключевой ставки на 50 б.п., до 5,50\% годовых [3], что объясняется возрастающими показателями инфляции. Предыдущее обращение к столь жестким мерам ДКП вызвало недоумение даже у опытных прогнозных аналитиков, включая Bloomberg, представлявший консенсус-прогноз в виде увеличения на 0, 25 п.п. Несмотря на уверения, что увеличение ставки практически не отразится на рынке ипотечного кредитования, следует признать, что это спорное утверждение, которое, исходя из анализа предыдущих схожих ситуаций, имеет следствие всегда сужение данного сегмента [4].

Принятые меры, как показывает незначительный временной отрезок, пока еще незначительно повлияли на значения ипотечных ставок. На это указывает проведенный «РБК-недвижимостью» опрос. Так, Райффайзенбанк снизил ставку по льготным программам: на новостройки на 0,2 п.п., до 5,69\%, для семей с детьми - на 0.4 п.п., до 4,59\%.

Инвестиционная составляющая покупки жилья в настоящее время исчерпана. Преимущественное число клиентов, приобретающих жилье из-за снижения ставок по депозитам, уже закрыло сделки. Цикл быстрого подорожания жилья исчерпан, и покупка новостроек в настоящее время не рассматривается как инвестиции, с учетом относительно невысоких арендных ставок. В настоящее время, как считается, рост ключевой ставки не отразился на рынке жилья. На рынок первичного жилья распространяется льготная ипотека. Ставка по ней является фиксированной и субсидируемой на государственном уровне. Таким образом, момент окончания данной программы, действующей до 1 июля 2021 г., или предполагаемое ограничение ее географии (Центробанк предлагает ограничить программу 24 регионами) окажет на ипотечный рынок большее влияние, чем рост ключевой ставки.

В преддверии завершения программы, по аналогии с ситуацией в 2018-2019 гг., может произойти всплеск спроса из-за покупателей, стремящихся зафиксировать низкие ипотечные ставки. Очевидно, наиболее вероятный сценарий продления госипотеки - ее трансформация в целевое субсидирование отдельных регионов или даже локаций. С одной стороны, это позволит рынку прийти к более сбалансированному состоянию. С другой, дает государству эффективный инструмент стимулирования конкретных местных рынков.

В годовом выражении ипотека пока растет: по данным Frank RG в первом квартале выдано почти 420 тыс. ипотечных кредитов на первичное и вторичное жилье, что на $21 \%$ выше по сравнению с 2020 г. Общая сумма достигла 1,17 трлн. руб., что на 40\% выше, чем годом ранеe.

До конца года, с учетом возможного роста ключевой ставки, ставки по ипотеке на новостройки могут колебаться в пределах 7,5-8,5\%, а на «вторичку» подняться до 9-10\%. Если будет увеличиваться ипотечная ставка, то возрастет ежемесячный платеж. В результате произойдет снижение спроса и цен на жилье. Согласно данным, повышение ставки на 1 п.п. приводит к увеличению ежемесячного платежа на $8 \%$. 
Прогнозируется, что по мере того, как экономические перспективы улучшаются благодаря прогрессу в борьбе с коронавирусом и изобретению вакцин, а также различным предпринятым мерам со стороны правительств большинства стран по сдерживанию экономической рецессии, повышаются ожидания экономического роста, что приводит к повышению ключевой ставки.

Ставки по ипотечным кредитам в настоящее время сохраняются на существующем уровне. Ряд банков даже предпринимает шаги по удержанию клиентов и привлечению новых в виде понижения ставок. Большая часть экономического восстановления всего мира - это постепенное возвращение людей к работе, которая будет, в значительной степени, зависеть от доступности вакцины от коронавируса. Ряд экспертов придерживается мнения, что ставки по ипотечным кредитам целесообразно поднимать, поскольку многие экономики уже вступили в стадии восстановления работоспособности экономики.

Но ставки по ипотеке могут оставаться низкими, если появятся неожиданные негативные новости, касающиеcя COVID-19 или задержками с распространением вакцины. И то, что происходит с фондовым рынком, также может повлиять на ставки. Когда именно ставки начнут расти и насколько они вырастут, зависит от нескольких факторов. Главное, на что следует обратить внимание это то, как происходит борьба с пандемией и ее воздействием на экономику. Но другие факторы, такие как инфляция, также будут влиять на ставки по ипотечным кредитам. То, что может показаться небольшим увеличением ставок, может иметь большое влияние на прибыль.

В мире уже наблюдается рост ставок примерно на 0,5\% с начала 2021 г. Так, например, в США для 30-лет- него жилищного кредита на сумму 300000 долларов этот рост увеличил ежемесячный платеж по этому типу кредита на 81 доллар. Согласно ипотечному калькулятору NextAdvisor, в течение срока действия аналогичной ссуды эти дополнительные 0,5\% будут стоить более 28000 долларов США в виде дополнительных процентов.

Основываясь на том, насколько низкими были процентные ставки в 2020 году, ряд экспертов придерживается мнения, что произойдет рост средней процентной ставки по ипотеке в 2021 году. Кризис COVID-19 был дефляционным событием, из-за которого ставки по ипотечным кредитам были ниже, чем они традиционно были бы при нормальной рецессии. Любое повышение ставок по ипотеке зависит от состояния экономики [6], и это зависит от того, как происходит улучшение экономики во время адаптации к пандемии.

Доход, а также финансовая помощь должны в определенной степени подстегнуть инфляцию, спрос должен вырасти, а рост экономик должен вернуться в нормальное русло. Медленный и устойчивый рост экономики будет основным драйвером более высоких ставок по ипотечным кредитам. Увеличение значения ключевой ставки, несомненно, окажет влияние на то, что после завершения льготной программы на новостройки ставки по кредитам, предоставляемым на приобретение жилья, увеличатся. Оценить влияние возросшей ключевой ставки на рынки недвижимости затруднительно.

Пандемии возникают экзогенно, и из-за уникальности возникшей ситуации доступность данных ограничена, в частности, из-за низкой частоты временных рядов по недвижимости. Кроме того, трудно изолировать влияние на рынок, поскольку на цены могут существенно влиять более крупные макроэкономические условия, которые окажут свое воздействие в отсроченном виде.

\section{ЛИТЕРАТУРА}

1. What causes mortgage rates to rise or fall? [Электронный ресурс]. — Режим доступа: https://www.stemlending.com/mortgage-rate-changes/ (дата обращения 11.06.2021)

2. ЦБ повысил ключевую ставку до 5\%. Насколько теперь подорожает ипотека? [Электронный ресурс]. — Режим доступа: https://realty.rbc.ru/ news/6082c4149a79471788b8751a (дата обращения 11.06.2021)

3. Банк России принял решение повысить ключевую ставку на 50 6.п. до 5,5\% годовых? [Электронный ресурс]. — Pежим доступа: https://www.cbr.ru/ press/keypr/ (дата обращения 11.06.2021)

4. В 2021 году ипотечный рынок ждет сокращение? [Электронный ресурс]. - Режим доступа: https://snews.ru/content/v-2021-godu-ipotechnyy-rynokzhdet-sokrashchenie (дата обращения 11.06.2021)

5. Число ипотечных кредитов на вторичном рынке в месяц [Электронный ресурс]. — Режим доступа: https://frankrg.com/datahub/category/mortgage/ figure/29455 (дата обращения 11.06.2021).

6. Попцова В.А. Ипотечное кредитование в России // Политика, экономика и инновации. 2016. № 2. С. 45-46.

(с) Метревели Елизавета Георгиевна ( metrevelieg@yandex.ru ).

Журнал «Современная наука: актуальные проблемы теории и практики» 